\title{
Transcriptome profiling of Kentucky bluegrass (Poa pratensis L.) accessions in response to salt stress
}

\author{
B. Shaun Bushman ${ }^{1 * \dagger}$, Keenan L. Amundsen ${ }^{2 \dagger}$, Scott E. Warnke ${ }^{3}$, Joseph G. Robins ${ }^{1}$ and Paul G. Johnson ${ }^{4}$
}

\begin{abstract}
Background: Kentucky bluegrass (Poa pratensis L.) is a prominent turfgrass in the cool-season regions, but it is sensitive to salt stress. Previously, a relatively salt tolerant Kentucky bluegrass accession was identified that maintained green colour under consistent salt applications. In this study, a transcriptome study between the tolerant (PI 372742) accession and a salt susceptible (PI 368233) accession was conducted, under control and salt treatments, and in shoot and root tissues.

Results: Sample replicates grouped tightly by tissue and treatment, and fewer differentially expressed transcripts were detected in the tolerant PI 372742 samples compared to the susceptible PI 368233 samples, and in root tissues compared to shoot tissues. A de novo assembly resulted in 388,764 transcripts, with 36,587 detected as differentially expressed. Approximately $75 \%$ of transcripts had homology based annotations, with several differences in GO terms enriched between the PI 368233 and PI 372742 samples. Gene expression profiling identified salt-responsive gene families that were consistently down-regulated in PI 372742 and unlikely to contribute to salt tolerance in Kentucky bluegrass. Gene expression profiling also identified sets of transcripts relating to transcription factors, ion and water transport genes, and oxidation-reduction process genes with likely roles in salt tolerance.

Conclusions: The transcript assembly represents the first such assembly in the highly polyploidy, facultative apomictic Kentucky bluegrass. The transcripts identified provide genetic information on how this plant responds to and tolerates salt stress in both shoot and root tissues, and can be used for further genetic testing and introgression.
\end{abstract}

Keywords: Poa pratensis, Kentucky bluegrass, Salinity stress, Transcriptome, RNA-seq, Salt tolerance

\section{Background}

Kentucky bluegrass (Poa pratensis L.) is a prominent cool-season perennial grass used as a turf amenity grass and as forage for livestock. It is a member of the Poa genus, including a range of high polyploid and facultative apomictic plants and populations [1]. As a turfgrass with a strong rhizomatous growth habit, Kentucky bluegrass is used in sports fields, golf course roughs and fairways, residential lawns, roadsides, and public parks. Many of these locations are accompanied by high

\footnotetext{
* Correspondence: shaun.bushman@ars.usda.gov

${ }^{\dagger}$ Equal contributors

${ }^{1}$ USDA-ARS Forage and Range Research Laboratory, 700 North 1100 East,

Logan, UT 84322-6300, USA

Full list of author information is available at the end of the article
}

salinity in soils or water, which imposes stress on the turf. High seasonal water tables that evaporate over the growing season in semi-arid environments increase the salinity levels in soils [2]. Salt water intrusions occur in coastal regions, roadsides receive substantial amounts of salt during winter de-icing, and increasing water restrictions in dry climates cause municipalities to use effluent water in landscape irrigation with higher concentrations of sodium chloride and other salts [3, 4]. Among cool-season $\left(\mathrm{C}_{3}\right)$ turfgrasses, Kentucky bluegrass is relatively intolerant of salinity stress [5]. However, previous evaluations of Kentucky bluegrass germplasm detected significant variation within the species for salinity tolerance [6-8]. 
Within the turfgrasses, salt stress causes a cessation of growth, leaf tip firing, negative leaf water potentials, a decrease in turf quality and functionality, and potentially plant death [9-11]. The mechanisms of plant salt tolerance include the exclusion of root salt uptake, osmotic adjustment, and compartmentalization or exclusion of $\mathrm{Na}+$ from above ground tissues [10, 12, 13]. Within Kentucky bluegrass, turf quality under salt stress was correlated with higher shoot and root growth, high relative water contents, and photochemical efficiency $[9,11$, 14, 15]. Additionally, although the actual physiological mechanisms are unknown, salt tolerance has been associated with foliar ABA application, antioxidant enzyme activities, reduced electrolyte leakage, and the presence of non-structural carbohydrates $[15,16]$.

Although previous studies have increased the understanding of Kentucky bluegrass responses to salinity stress, and identified salt-stress indicator measurements, very little information is available about the genetic mechanisms involved in Kentucky bluegrass responses to salinity stress. With no draft genome and minimal EST sequences available [17], and with no close relationships to other grass species that have reference genome libraries, Kentucky bluegrass functional genomics studies remain at the gene discovery phase. The advent of RNAseq studies has provided powerful methods to identify gene transcripts that vary upon salinity stress [18]. Through the identification of transcripts that vary significantly between control and salt treatment as well as between salt treated susceptible and tolerant germplasm sources, inferences can be made about which genes and genetic pathways in Kentucky bluegrass play a role in salinity stress response and tolerance.

In the present study, we utilized transcriptome sequencing to identify genes induced or repressed in a Kentucky bluegrass salt tolerant accession relative to a susceptible accession upon salt treatment. Replications of both shoot and root tissues are examined under control and salt-stressed treatments, in both a tolerant and susceptible accession. We use a de novo assembly as a reference sequence library to map sequences and determine differential gene expression. This is the first report of Kentucky bluegrass differential gene expression analysis on a transcriptome scale, and provides insight into genes and networks that contribute to salinity response, and tolerance, in this turf species.

\section{Results and discussion}

Biological triplicates of a previously reported salt tolerant (PI 372742, shortened hereafter to 742) and a susceptible (PI 368233 shortened hereafter to 233) Kentucky bluegrass accession, under control and salt treatments, with shoot and root tissues separated, were sampled for transcriptome analysis. These samplings occurred 21 days after salt treatments were initiated, and one hour after the most recent salt treatment. As gene expression responses to salt stress can vary over time from the application of salt treatments [19], this sampling was selected to focus on transcripts with different abundances after several weeks of salt treatment.

Between 7.5 and 29.7 million Ion Torrent Proton reads, with an average of 18 million, were obtained per sample (Table 1). The read length ranged from 71 to $139 \mathrm{bp}$, with an average of $107 \mathrm{bp}$. A multidimensional scaling (MDS) plot of distances between average log expression values among trimmed sample replications indicated consistency among genotypes, tissues, and replications within treatments (Fig. 1). The first dimension separated shoot from root tissue samples, while the second separated control from salt treated samples. The separation of control and salt treated groups for the 233 samples was more pronounced than 742 sample groups. The lesser separation among 742 replicate groups relative to 233 replicate groups may have occurred if fewer 742 genes were differentially expressed compared to 233 ,

Table 1 Poa pratensis samples sequenced for differential expression analysis of PI 372742 (742) and PI 368233 (233) biological replicates

\begin{tabular}{|c|c|c|c|c|}
\hline Sample ID & Salinity Trait & Tissue & Treatment & Num. Seq. Reads \\
\hline $742-s 1$ & tolerant & root & control & 13558389 \\
\hline $742-s 2$ & tolerant & root & control & 10274146 \\
\hline $742-53$ & tolerant & root & control & 10041844 \\
\hline $742-s 1$ & tolerant & root & salt & 26109832 \\
\hline $742-s 2$ & tolerant & root & salt & 22046527 \\
\hline $742-53$ & tolerant & root & salt & 13598513 \\
\hline $742-s 1$ & tolerant & shoot & control & 7557854 \\
\hline $742-\$ 2$ & tolerant & shoot & control & 10806950 \\
\hline $742-53$ & tolerant & shoot & control & 29725583 \\
\hline $742-s 1$ & tolerant & shoot & salt & 10954593 \\
\hline $742-s 2$ & tolerant & shoot & salt & 16140076 \\
\hline $742-s 3$ & tolerant & shoot & salt & 16022650 \\
\hline 233-s1 & susceptible & root & control & 23578353 \\
\hline $233-s 2$ & susceptible & root & control & 20700915 \\
\hline $233-53$ & susceptible & root & control & 21363835 \\
\hline 233-s1 & susceptible & root & salt & 20326506 \\
\hline $233-s 2$ & susceptible & root & salt & 19285845 \\
\hline $233-53$ & susceptible & root & salt & 21664782 \\
\hline 233-s1 & susceptible & shoot & control & 19516703 \\
\hline $233-52$ & susceptible & shoot & control & 22296639 \\
\hline $233-53$ & susceptible & shoot & control & 18409067 \\
\hline 233-s1 & susceptible & shoot & salt & 20772258 \\
\hline $233-52$ & susceptible & shoot & salt & 21847645 \\
\hline $233-s 3$ & susceptible & shoot & salt & 19813265 \\
\hline
\end{tabular}




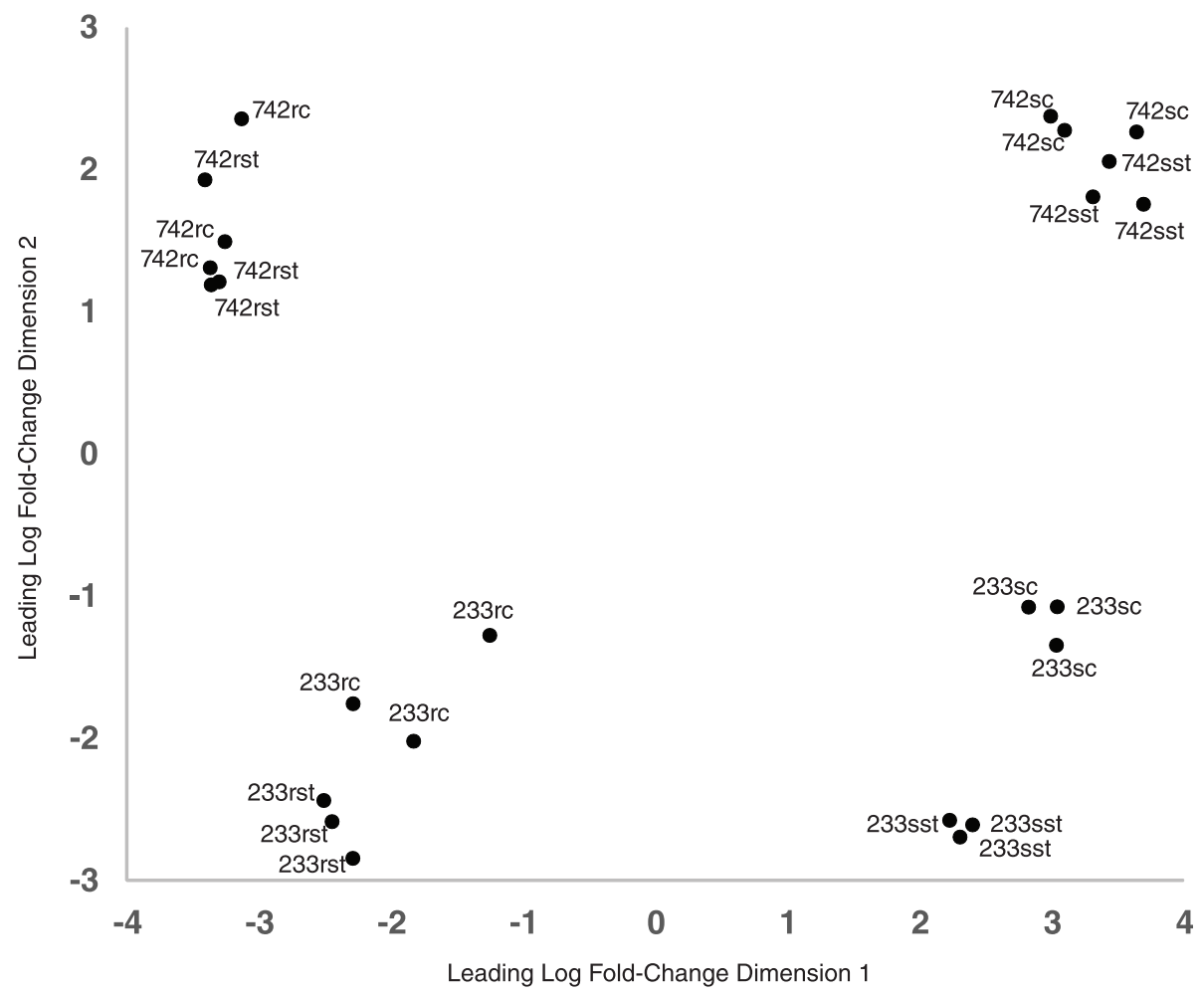

Fig. 1 Multidimensional scaling plot of log fold changes among three replicate samples of PI 372742 (742) and PI 368233 (233), with rC = control root samples, rst = root salt-treated samples, sc = shoot control samples, and sst = shoot salt-treated samples

or if the 233 samples were more genetically variable than the 742 samples. As both of these accessions are highly apomictic (unpublished data), and 742 had higher (rather than lower) standard deviations upon salt stress than 233 in a previous study [7], the lesser separation within 742 replicate groups more likely resulted from fewer genes responding to salt stress rather than lower inherent variation.

Trimmed sequencing reads from both accessions and all samples were used to make a de novo reference assembly, resulting in 388,764 transcripts. The high number of transcripts in the assembly resulted from the combination of two genotypes that were included in the assembly, the high mixed auto- and allo-polyploidy of Poa pratensis, and the apomictic breeding system of Poa pratensis with its high and fixed heterozygosity [1]. The N50 of this assembly was $358 \mathrm{bp}$, the average length $360 \mathrm{bp}$, and the maximum transcript assembly length was 8849 bp.

A total of 36,587 differentially expressed transcripts were detected; with 20,430 from shoot tissues and 16,157 from root tissues. These differentially expressed transcripts were identified from four pairwise comparisons: 233 salt treated vs. control, 742 salt treated vs. control, 742 control vs. 233 control, and 742 salt treated vs. 233 salt treated samples (Fig. 2). Consistent with the
MDS plot, fewer differentially expressed transcripts were detected in the tolerant 742 salt treated vs. control samples (1478 in shoots and 802 in roots) when compared to the susceptible 233 salt treated vs. control samples (12,597 in shoots and 3802 in roots; Fig. 2). Additionally, the 742 salt treated vs. 233 salt treated comparison had almost double the number of differentially expressed transcripts compared to the 742 control vs. 233 control comparison; highlighting a widening difference in gene expression responses between these two genotypes upon salt stress imposition.

For both shoot and root tissues, several groups of transcripts shown in the Venn diagrams were unlikely to contribute to salt tolerance in the 742 accession. Transcripts specific to each individual comparisons (dark gray, Fig. 2) reflected an absence of responses among any other comparison, and were thus removed from further analysis. Venn groups shown in light gray (Fig. 2) were transcripts with profiles that varied between 742 and 233 backgrounds but were not induced or repressed by salt stress, which would require further genotypes to infer a role in salt tolerance. Also shown in light gray were transcripts that exhibited similar responses in both 742 and 233 upon salt treatment. These groups of transcripts were also removed from further analysis. The remaining Venn groups (white, Fig. 2), which included 


\section{A - shoot tissue}

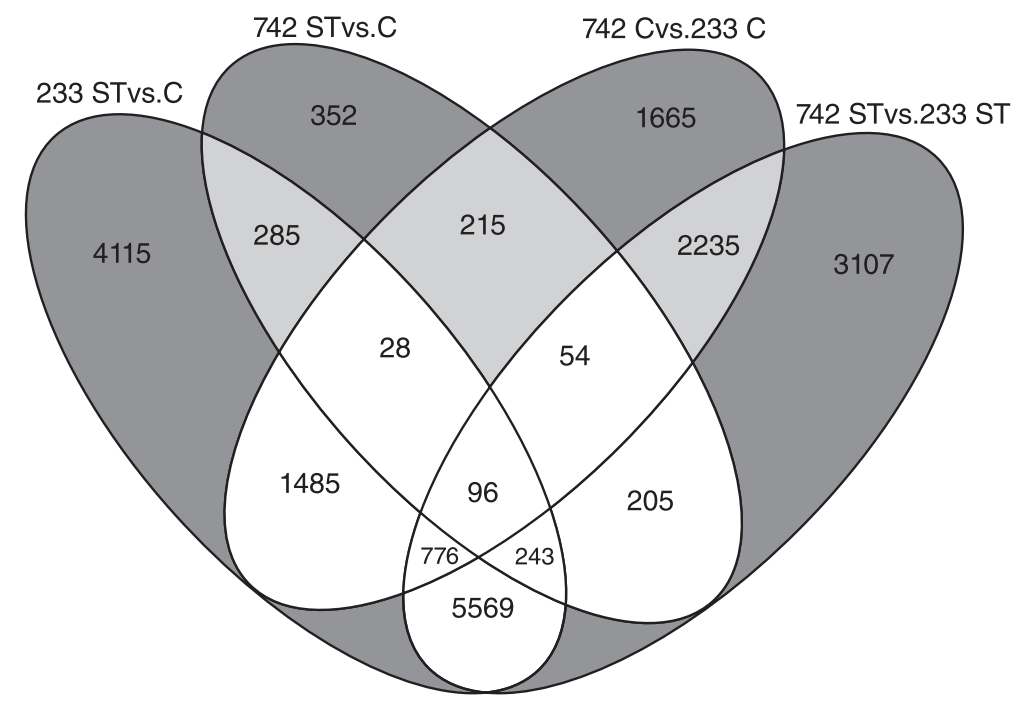

$B$ - root tissue

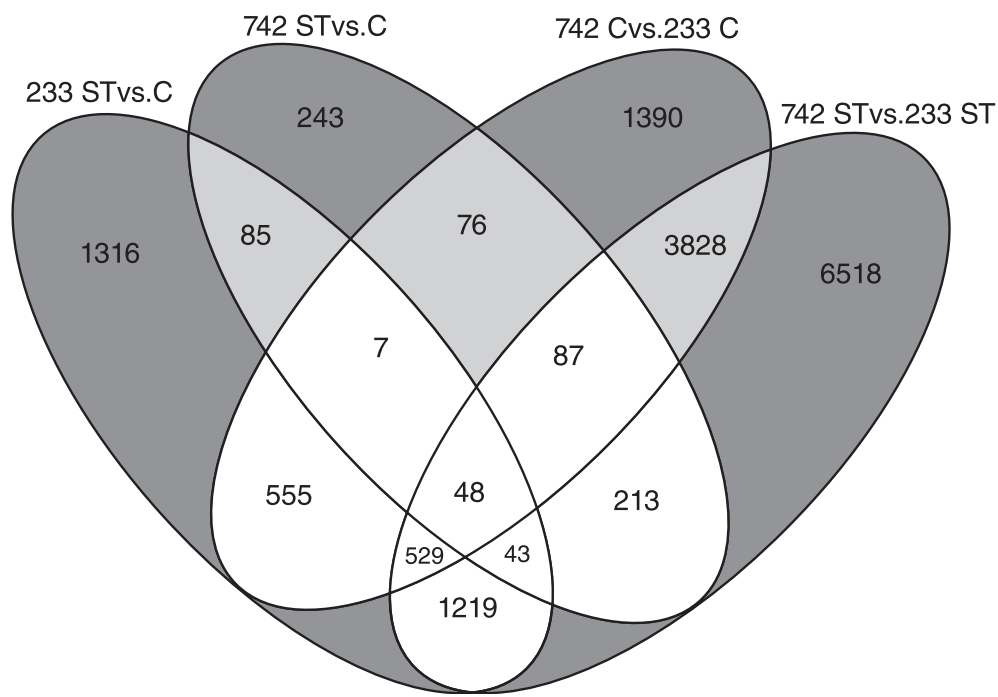

Fig. 2 Venn diagram of the numbers of differentially expressed transcripts among four pairwise comparisons from shoot (a) and root (b) tissue comparisons. PI 368233 (233) is a salt susceptible and PI 372742 (742) a salt tolerant Kentucky bluegrass genotype. ST = salt treatment of 9 dS/m saline solution while $\mathrm{C}$ = control treatment of $1 \mathrm{dS} / \mathrm{m}$ solution. Sample groups in dark gray and light gray represent transcripts unlikely to contribute to tolerance; and groups in white include transcripts with possible roles in the salt tolerance of 742

8456 transcripts from shoots and 2701 from roots, possessed expression profiles with the potential to be associated with salt tolerance in the 742 accession. Of those shoot differentially expressed transcripts, $77 \%$ had BLASTx hits and $69 \%$ had GO terms associated with previously reported sequences. For root transcripts, $74 \%$ had Blastx hits and $64 \%$ had associated GO terms. Although no close relative with substantial sequence information available exists for Poa pratensis, Hordeum vulgare and other Triticeae species, along with Brachypodium distachyon, had the highest proportion of top hits to Poa pratensis transcripts. The transcript identifiers and normalized expression values of these differentially expressed transcripts of potential interest are listed in Additional files 1 and 2: Tables S1 and S2.

Previous reports proposed that salt sensitive and salt tolerant species share the same genes involved in their response to salt stress, but that tolerant species either contain more effective alleles of the genes or implement the genes in a more effective manner to reduce salt stress [18]. Consistent with this hypothesis, the percentages of transcripts in the different GO functional groups 
in our study were similar (Fig. 3) and not inconsistent with ion or osmotic stressed studies [20]. Furthermore, we conducted enrichment tests of $\mathrm{GO}$ terms between the 742 salt treated vs. control and the 233 salt treated vs. control comparisons, and found few GO terms enriched between 742 and 233 in either root or shoot datasets (Table 2). In shoot tissues, sequences involved in $\mathrm{N}$-terminal protein lipidation processes were enriched in 742 samples relative to 233 samples, suggesting an increased need to transport modified proteins to membranes to adjust for osmotic stress [21]. In root tissues, sequences with endonuclease and alpha-glucosidase activity were enriched in 742 samples while sequences in the cytoplasmic and intracellular components were enriched in 233 samples. Interestingly, several GO terms were present in roots but not shoots, and vice versa

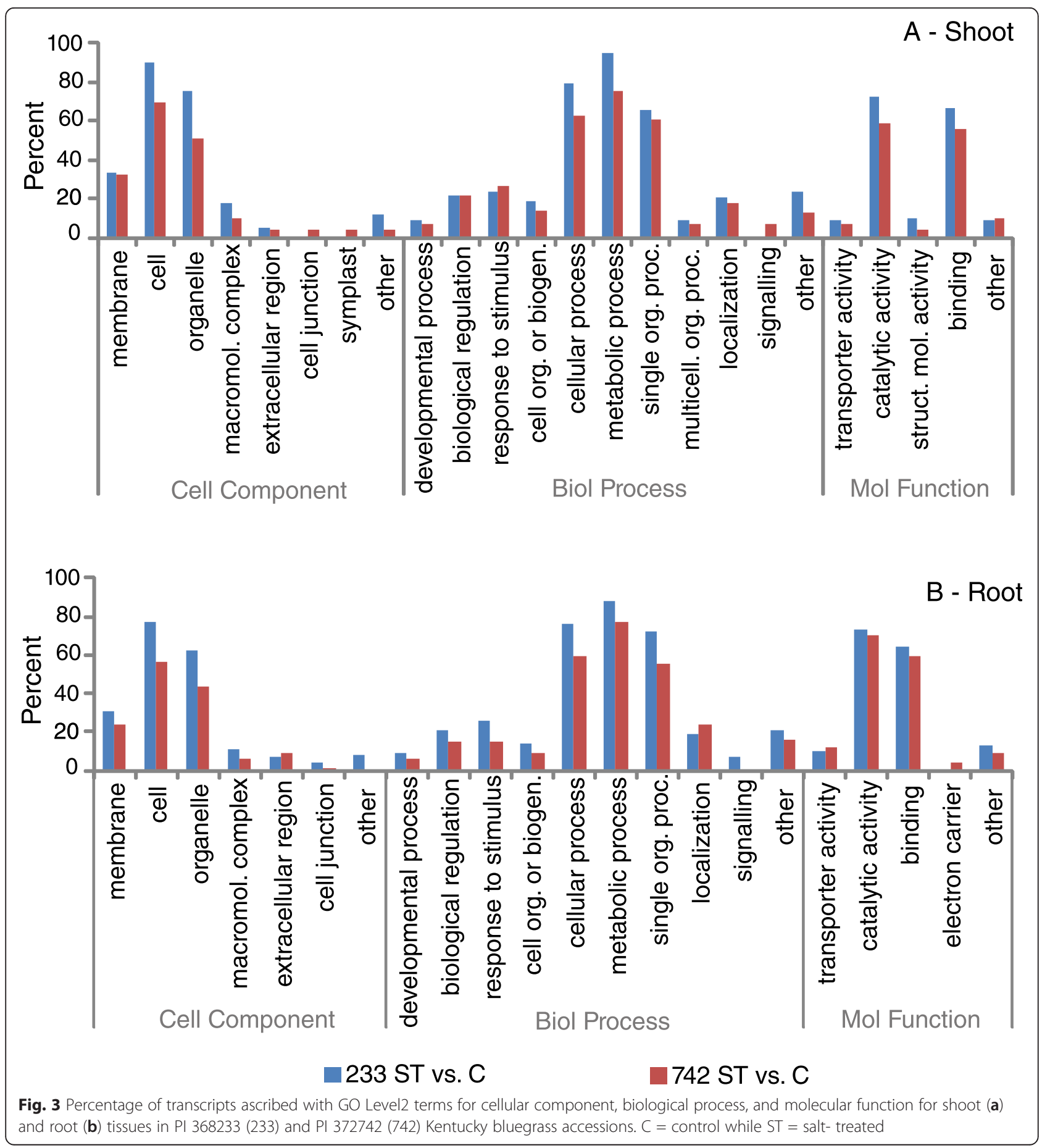


Table 2 Enriched GO terms in shoot and root tissues when PI 372742 (742) salt treated vs. control sequences were tested against PI 368233 (233) salt treated vs. control sequences

\begin{tabular}{|c|c|c|c|c|c|c|}
\hline $\mathrm{GO}$ ID & GO Term & Category & FDR & $P$-value & 742 Seqs $^{a}$ & 233 Seqs $^{a}$ \\
\hline \multicolumn{7}{|l|}{ Shoots } \\
\hline GO:0006498 & $\mathrm{N}$-terminal protein lipidation & Biol. Process & $3.75 \mathrm{E}-02$ & 4.65E-05 & $4 / 626$ & $4 / 8197$ \\
\hline GO:0044424 & intracellular & Cell. Component & $3.75 \mathrm{E}-02$ & 3.87E-05 & $80 / 626$ & $3459 / 8197$ \\
\hline \multicolumn{7}{|l|}{ Roots } \\
\hline GO:0004519 & endonuclease activity & Mol. Function & $6.28 \mathrm{E}-04$ & $1.86 \mathrm{E}-07$ & $8 / 398$ & $2 / 2401$ \\
\hline GO:0090599 & alpha-glucosidase activity & Mol. Function & $1.57 \mathrm{E}-02$ & $3.71 \mathrm{E}-05$ & $5 / 398$ & $1 / 2401$ \\
\hline GO:0044444 & cytoplasmic part & Cell. Component & $1.20 \mathrm{E}-02$ & 1.42E-05 & $45 / 398$ & $698 / 2401$ \\
\hline GO:0044424 & intracellular part & Cell. Component & 1.97E-02 & 5.23E-05 & $60 / 398$ & $827 / 2401$ \\
\hline
\end{tabular}

${ }^{\mathrm{a}}$ The number of sequences with that GO term over the total number of sequences tested

(Fig. 3). Shoot tissues included sequences in the symplast cellular component while roots did not, suggesting that roots exhibited tighter control of water and solute movement in both accessions. In the molecular function GO category, shoots also included sequences with structural molecule activity while roots included sequences with electron carrier activity (Fig. 3). In particular the electron carrier activity detected in roots through GO terms may point to its role in generating transmembrane electrochemical gradients in response to elevated levels of salt.

From the prioritized Venn groups (white, Fig. 2), transcripts were further extracted with expression values that were (1) consistently induced in 233 salt treated vs. control, 742 salt treated vs. control, and 742 salt treated vs. 233 salt treated; (2) consistently repressed in the same three comparisons; or (3) contrasting in 742 responses upon salt treatment compared to 233. These comparisons yielded 702 transcripts from shoot tissues and 339 from root tissues. Only 70 of those differentially expressed transcripts were shared between both tissues, highlighting tissue specific genetic mechanisms for salt response. The transcript abundances, P-values, annotations, and GO terms for these transcripts in both tissues are listed in Additional files 3 and 4 (Tables S3 and S4).

\section{Root tissue}

Few genes such as transcription factors, oxidative stress response genes, or ion transporters have been reported as induced upon salt stress in roots of salt-sensitive species, relative to above-ground plant tissues [18, 19, 22]. Of these genes however, transcription factors can activate downstream stress-response effectors [18, 23]. In this study, bZIP, MYB, AP2, WRKY, and NAC and Homeobox transcription factors were extracted out of the Venn groups of interest (Fig. 2) using an HMM search as well as GO Biological Process terms of 'regulation of transcription.' Ten transcripts were detected (Fig. 4). A senescence associated transcription factor, WRKY46, Hox5, and a bZIP transcription factor were down-regulated in 742 while two MYB, three homeobox, and a zinc finger transcription factor were up-regulated in 742. The MYB-like gene MYBas2, up-regulated in both 233 and 742 but expressed at a higher level in 742, is homologous to a splice variant of AtMYB59 [24] that represses root cell growth and elongation [25]. The Knotted-1 homeobox transcription factor can also function as a negative repressor of meristematic growth [26]. This apparent down-regulation of root growth suggests a possible method by which 742 may be tolerating salt; by slowing its root elongation into saline soil areas to avoid uptake of excess sodium. Alternatively, tolerance may also be improved through a kinase signalling cascade, possibly mediated by the A20/AN1 zinc finger factor [27] or other MYB transcripts [28].

Terrestrial plants generally share the same small complement of ion transporters [22]. Several transporters have been implicated in movement of salt from the soil into the root zone, in movement of sodium out of the xylem or phloem to prevent shoot accumulation, in movement of sodium from the cytosol into the extracellular matrix, or movement from the cytosol to vacuoles [22]. In this study's root samples, transcripts with Biological Process terms of 'transmembrane transport', 'ion transport', and 'water transport' were extracted from the Venn groups of interest (white, Fig. 2) and exhibited variable expression profiles in 742 salt treated samples (Fig. 5). Of eleven extracted transcripts, an aquaporin, cation antiporter, and calcium-transporting ATPase were down-regulated, suggesting a reduction in water and ion transport into the roots in response to osmotic stress to reduce sodium influx. Two carbohydrate related transporters, a manganese transporter, and a V-type proton ATPase subunit were up-regulated in 742 .

Reactive oxygen species are naturally produced during photosynthesis and respiration [29], but are induced upon salt stress in plants [30]. Transcripts involved in the 'oxidation-reduction process' and 'response to oxidative stress' Biological Process terms were extracted from the Venn groups of interest (Fig. 2). Seventeen 


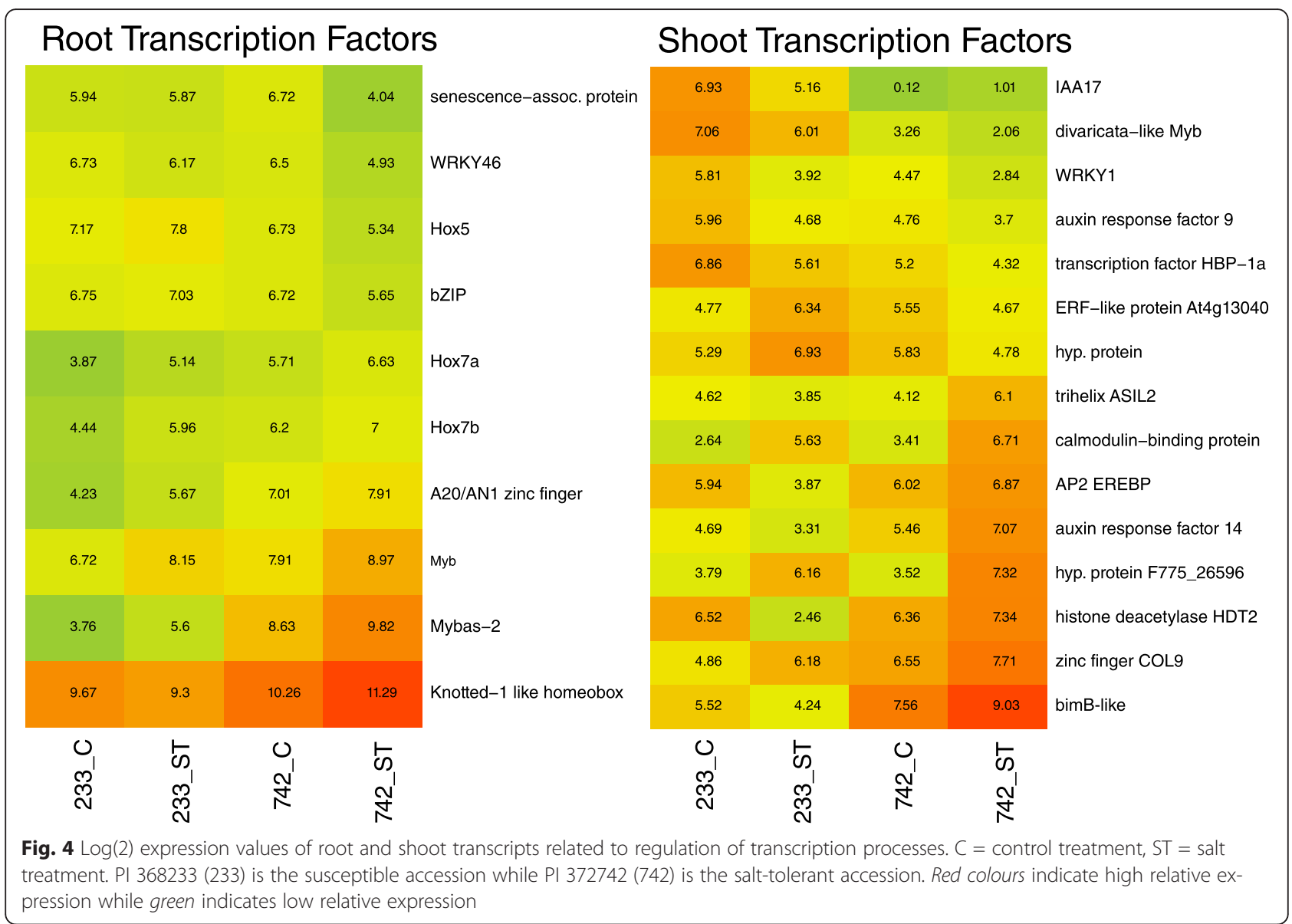

transcripts were down-regulated in 742 salt treated samples relative to other samples (Fig. 6), including all the peroxidases and a cytochrome $\mathrm{p} 450$. Although peroxidases are common enzymes for detoxifying reactive oxygen species in plants, their reduced transcript abundances indicate that they were not functioning in that role in Kentucky bluegrass. Four transcripts were up-regulated in 742, including a glutathione-Stransferase, a glutamate synthase, and a glyceraldehyde3-phosphate dehydrogenase (G3PDH). Each of these upregulated genes can be induced upon abiotic stress, and are likely to be involved in detoxification of the deleterious oxidative stress compounds [31-33].

Other transcripts within the Venn groups of interest (Fig. 2), which were up- or down-regulated in both 233 and 742 upon salt treatment but induced to a greater degree in 742, or contrastingly regulated between 742 and 233 (Additional file 3: Table S3), were detected. These included transcripts with homology to genes with kinase activity, fructan biosynthesis, endonuclease activity, and genes without homology based annotations. Interestingly, most of these were down-regulated in 742 (Additional file 3: Table S3).

\section{Shoot tissue}

Similar to root tissue studies, bZIP, MYB, AP2, WRKY, NAC, Homeobox, and other transcription factors were extracted out of the shoot-expressing Venn groups of interest (Fig. 4). Of 15 transcripts detected, seven were down-regulated; including auxin responsive IAA17 and ARF9 genes and an ethylene response factor (ERF). These two auxin responsive genes may form heterodimers to exert signalling effects [34]. ERF transcription factors play roles in abiotic stress tolerance [35], but the up-regulation in the susceptible 233 and the down-regulation in the tolerant 742 suggests that this transcription factor may rather be signalling genes that respond to salt stress and not tolerate the stress. Eight transcripts were upregulated, including a COL9 homolog that can function to delay flowering by repressing the expression of CO [36], and an AP2-EREBP transcription factor homolog that may be involved in multiple abiotic stress responses [37]. Interestingly, another auxin response factor (ARF14) was up-regulated in 742, highlighting specific and varied roles of auxin mediated responses to salt stress in these samples. 


\begin{tabular}{|c|c|c|c|c|c|c|c|c|c|}
\hline \multicolumn{4}{|c|}{ Root Transport Processes } & & \multicolumn{4}{|c|}{ Shoot Transport Processes } & \multirow{3}{*}{$\begin{array}{l}\text { protein LOC100846504 } \\
\text { At1g06890-like }\end{array}$} \\
\hline \multirow[t]{2}{*}{9.45} & \multirow{2}{*}{8.44} & \multirow{2}{*}{2.97} & \multirow{2}{*}{1.91} & \multirow{2}{*}{ aquaporin NIP2-1 } & 6.37 & 4.74 & 0 & 0 & \\
\hline & & & & & 5.9 & 4.76 & 0.35 & 0 & \\
\hline \multirow[t]{2}{*}{7.94} & 6.37 & 5.35 & 2.48 & cation $\mathrm{h}(+)$ antiporter 19 & 6.04 & 3.66 & 3.08 & 2.38 & peptide transporter PTR2 \\
\hline & \multirow[b]{2}{*}{5.7} & \multirow[b]{2}{*}{4.68} & \multirow[b]{2}{*}{3.68} & \multirow[b]{2}{*}{ boron transporter } & 6.2 & 3.92 & 3.62 & 2.77 & aquaporin NIP2-1 \\
\hline 6.84 & & & & & 7.19 & 8.36 & 4.9 & 3.19 & zinc induced facilitator 1 \\
\hline \multirow{2}{*}{6.89} & \multirow{2}{*}{6.63} & \multirow{2}{*}{6.9} & \multirow{2}{*}{5.28} & \multirow{2}{*}{$\begin{array}{l}\text { calcium-transporting ATPase } \\
\text { plasma membrane-type }\end{array}$} & 7.52 & 7.79 & 7.43 & 5.3 & calcium-transporting ATPase \\
\hline & & & & & 6.92 & 7.18 & 6.67 & 5.67 & sphingolipid transporter spinster \\
\hline 4.19 & 4.56 & 3.88 & 5.81 & monosacc.-sensing protein 2 & 4.28 & 3.55 & 4.91 & 6.07 & polyol transporter 5 \\
\hline \multirow[b]{2}{*}{7.9} & \multirow[b]{2}{*}{1.74} & \multirow[b]{2}{*}{3.87} & \multirow[b]{2}{*}{6.8} & \multirow[b]{2}{*}{ HIAT-1 } & 5.63 & 3.98 & 4.75 & 6.08 & TIP \\
\hline & & & & & 6.37 & 4.35 & 5.13 & 6.53 & sugar carrier protein $C$ \\
\hline \multirow[t]{2}{*}{5.42} & \multirow{2}{*}{6.56} & \multirow{2}{*}{6.79} & \multirow[t]{2}{*}{7.58} & \multirow[t]{2}{*}{ Mn-transporting ATPase PDR2 } & 5.38 & 5.64 & 5.26 & 6.63 & vacuolar ATP synthase $16 \mathrm{kda}$ \\
\hline & & & & & 6.66 & 3.93 & 5.74 & 7.06 & aquaporin NIP1-1 \\
\hline 5.41 & 7.39 & 7.41 & 8.24 & V-type proton atpase subunit d & 6.1 & 5.88 & 5.81 & 7.08 & aquaporin TIP4-1 \\
\hline \multirow[b]{2}{*}{7.59} & \multirow{2}{*}{7.42} & \multirow{2}{*}{7.45} & \multirow[b]{2}{*}{8.48} & \multirow{2}{*}{ monosacc.-sensing protein $2 \mathrm{~b}$} & 5.44 & 4.44 & 6.08 & 7.22 & carrier protein \\
\hline & & & & & 7.32 & 6.32 & 6.41 & 7.97 & inorg. phos. transporter 1 \\
\hline 6.72 & 4.61 & 8.48 & 8.49 & plastidic dicarboxylate transporter & 4.69 & 6.55 & 6.57 & 8.25 & vacuolar cation proton exchanger \\
\hline & & & & & 8.67 & 7.15 & 7.89 & 9.15 & ubiquitin-60s protein 140 \\
\hline 7.78 & 6.33 & 9.44 & 9.53 & triosephosphate cytosolic & 5.51 & 6.96 & 7.46 & 9.33 & V-type proton ATPase d \\
\hline $\begin{array}{l}\text { U, } \\
\mathscr{N}^{\prime}\end{array}$ & $\begin{array}{l}\mathfrak{n}_{1} \\
\mathfrak{n}_{N}\end{array}$ & \begin{tabular}{l} 
N \\
\multirow{N}{N}{}
\end{tabular} & $\begin{array}{l}\leftarrow \\
\text { ฯ } \\
\text { ป }\end{array}$ & & $\begin{array}{l}u_{1} \\
\mathscr{N}^{\prime}\end{array}$ & $\begin{array}{l}\mathfrak{n}_{1} \\
\mathfrak{N}_{N}\end{array}$ & $\begin{array}{l}\mathcal{N} \\
\text { N }\end{array}$ & $\begin{array}{l}\mathfrak{s}_{1} \\
\stackrel{N}{N}\end{array}$ & \\
\hline $\begin{array}{l}\text { Fig. } 5 \text { Lo } \\
\text { treatment } \\
\text { relative ex }\end{array}$ & 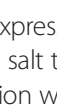 & ues & . & $\begin{array}{l}\text { loot transcripts related to io } \\
\text { is the susceptible accession } \\
\text { elative expression }\end{array}$ & $\begin{array}{l}\operatorname{tran} \\
\text { e PI } 3\end{array}$ & ane & rt & $\begin{array}{l}\text { biologi } \\
\text { t t acces }\end{array}$ & $\begin{array}{l}\text { cal processes. C = control } \\
\text { sion. Red colours indicate high }\end{array}$ \\
\hline
\end{tabular}

Shoot transcripts with Biological Process terms of 'transmembrane transport', 'ion transport', and 'water transport' were extracted from the Venn groups of interest (Fig. 5). Eighteen transport-related transcripts were extracted, and unlike the root tissue transport transcripts there were more up-regulated transcripts in the shoot tissues in 742 than there were down-regulated transcripts. Three aquaporins were differentially expressed in the shoot tissues; one down-regulated and two upregulated in 742. The aquaporin NIP2-1 was downregulated in both shoots and roots, which may contribute to a tolerant plant's reduction in hydraulic conductivity following salt imposition, or play a role in stomatal conductance [38]. The V-type ATPase subunit, induced in shoot tissue of 742 but also induced in root tissues, provides a capability for cells to maintain $\mathrm{pH}$ and power vacuolar sequestration of sodium ions [37]. Along with the vacuolar cation proton exchanger [39], TIP genes, the V-type ATPase induced transcripts could provide for more efficient sequestration of sodium ions into the vacuoles in tolerant 742 plants upon salt stress.

Shoot transcripts involved in the 'oxidation-reduction process' and 'response to oxidative stress' Biological Process terms were extracted from shoot-expressing Venn groups of interest. Forty-one transcripts involved in these oxidoreductase processes were extracted, with approximately half up- and half down-regulated in the 742 salt treated samples (Fig. 6). Similar to root tissues, several common antioxidant enzyme families such as peroxidases and laccases were down-regulated in the tolerant 742 . These would not be candidates for gene introgression to improve salt tolerance in more susceptible Kentucky bluegrass varieties. Other common antioxidant enzyme families included both up- and down-regulated gene members; such as cytochrome p450s, ferritins, and genes involved in polyphenol biosynthesis and metabolism. Transcripts induced in 742 included well characterized antioxidant enzymes such as superoxide dismutase [40], thioredoxin, G3PDH, and a protochlorophyllide gene. Some of these induced transcripts, such as superoxide dismutase and thioredoxin, were also detected in a barley study after 21 days of salt treatment [41].

Other transcripts within the Venn groups of interest (Fig. 3) were also up- or down-regulated in 742 salt treated samples (Additional file 4: Table S4). Several transcripts homologous to kinases, endonucleases, and heat shock proteins were detected, as well as many transcripts with no homology-based annotations.

\section{Conclusions}

These data represent the first RNA-seq analysis of the glycophytic Kentucky bluegrass, and provide gene 


\begin{tabular}{|c|c|c|c|c|}
\hline 8.33 & 6.25 & 5.58 & 2.37 & peroxidase $\mathrm{p} 7$ \\
\hline 6.06 & 5.58 & 6.7 & 2.78 & GзPDH type I \\
\hline 6.53 & 5.28 & 6.32 & 2.97 & 4-HPPD \\
\hline 7.17 & 6.09 & 3.41 & 3.03 & zinc-binding dehydrogenase \\
\hline 6.36 & 5.25 & 4.95 & 3.13 & pyruvate dehydrogenase e 1 alpha \\
\hline 7.16 & 5.27 & 4.98 & 3.37 & glucose-6-P 1-dehydrogenase \\
\hline 6.58 & 5.32 & 5.23 & 4.06 & 12-oxophytodienoate reductase 1 \\
\hline 7.14 & 8.67 & 5.08 & 4.15 & sarcosine oxidase \\
\hline 6.81 & 5.61 & 4.87 & 4.38 & geraniol 8-hydroxylase \\
\hline 6.61 & 6.47 & 6.37 & 5.05 & peroxidase 12 \\
\hline 5.72 & 6.2 & 6.3 & 5.08 & S-norcoclaurine synthase 1 \\
\hline 7.16 & 6.81 & 6.83 & 5.64 & ubiquitin carboxyl-terminal hydrolase \\
\hline 6.95 & 7.63 & 6.73 & 5.68 & dihydropyrimidine dehydrogenase \\
\hline 7.81 & 7.93 & 7.91 & 6.32 & cyp450 71c1 \\
\hline 8.03 & 7.35 & 6.67 & 5.22 & peroxidase 49 \\
\hline 9.01 & 6.77 & 6.78 & 5.11 & peroxidase 2 \\
\hline 9.64 & 8.01 & 7.28 & 6.62 & peroxidase 15 \\
\hline 4.16 & 4.09 & 4.96 & 6.2 & iron ion binding protein \\
\hline 4.09 & 3.24 & 4.72 & 6.66 & glutathione S-transferase T3 \\
\hline 9.29 & 7.9 & 10.29 & 10.38 & ferredoxin-dep. glutamate synthase \\
\hline 9.33 & 7.89 & 10.43 & 10.74 & GAPDH \\
\hline $\begin{array}{l}\text { U, } \\
\text { ల్ల }\end{array}$ & 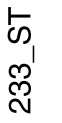 & $\begin{array}{l}\text { U } \\
\text { N } \\
\text { N }\end{array}$ & $\begin{array}{l}\qquad \\
\mathscr{N} \\
\text { N } \\
\text { J }\end{array}$ & \\
\hline
\end{tabular}

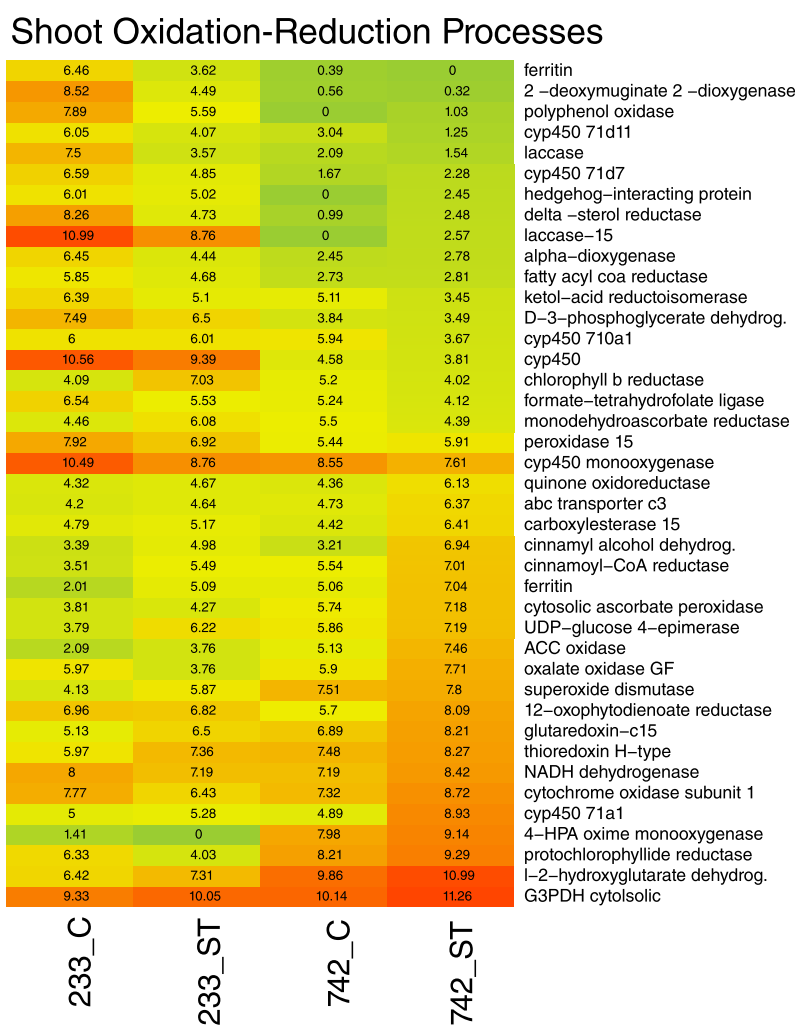

Fig. 6 Log(2) expression values of root and shoot transcripts related to oxidation-reduction biological processes. $C=$ control treatment, ST = salt treatment. PI 368233 (233) is the susceptible accession while PI 372742 (742) is the salt-tolerant accession. Red colours indicate high relative expression while green indicates low relative expression

candidates for tolerance to salt stress in this turfgrass species. Between shoot and root tissues, over 1000 transcripts with expression profiles consistent with conferring tolerance in the 742 accession were detected. By categorizing expression profiles into groups of transcripts that may contribute to salt tolerance in the 742 accessions, genes involved as transcription factors, water and ion transport processes, and oxidation-reduction processes, promising genes for further functional testing were identified and genetic mechanisms specific to Kentucky bluegrass under this treatment were inferred. As this experiment was treated for 21 days prior to sampling, most evanescent gene expression changes, including those that accommodate the initial osmotic and ionic shocks [19], would have returned to homeostasis and not be detected in this study. Gene families in those evanescent categories may include the peroxidases, ferretin, and cyp450, as they were either down-regulated or contained multiple gene family members with varying expression profiles. Additionally, in root tissues, ion and water transporting transcripts were predominantly down-regulated possibly to adjust for osmotic differences from the saline water in the soils [42].

Several transcriptions factors induced both in shoot and root tissues showed expression patterns consistent with roles in salt stress response, and their differential expression in PI 372742 suggests a role in conferring salt tolerance. Additionally, shoot vacuolar transporting transcripts were up-regulated to facilitate sequestration of sodium ions, and several oxidation-reduction process genes were detected in shoots that may help attenuate oxidative stress. Although further functional testing in a broader array of Poa pratensis germplasm is necessary to confirm a wider scope of inference in their roles in salt tolerance, these genes provide a deeper understanding of which mechanisms in Poa pratensis roots and shoots respond to, and tolerate, salinity stress.

\section{Methods}

\section{Salt treatment and sample collection}

Based on previous greenhouse salinity stress trials [7], two accessions of $P$. pratensis from the National Plant Germplasm System were used; the salt tolerant PI 372742 (shortened to 742) and the susceptible PI 368233 (shortened to 233). Seed from these two accessions was germinated on blotter paper and transferred to 70-grit silica sand in $5 \mathrm{~cm}$ cone-tainers (Stuewe and Sons, Tangent, OR). Plants were maintained in a glasshouse in Logan, UT, with $25{ }^{\circ} \mathrm{C} / 15{ }^{\circ} \mathrm{C}$ day/night temperatures, $13 \mathrm{~h}$ of light with an average PAR of $200 \mu \mathrm{M}$ (range 80-620), 
and $35 \%$ relative humidity. Plants were irrigated twice weekly, through submersion for $30 \mathrm{~s}$, in a nutrient solution containing a balance of macro- and micro-nutrients [43] but no sodium chloride. The nutrient solution electrical conductivity (E.C.) was $3.1 \mathrm{dS} / \mathrm{M}$ giving a soil E.C. of $0.9 \mathrm{dS} / \mathrm{M}$. At the five tiller stage, control plants were maintained with the same nutrient and irrigation regime while treated plants were submersed in the nutrient solution appended with $30 \mathrm{mM}$ sodium as sodium chloride and $75 \mathrm{mM}$ calcium chloride (to maintain the sodium absorption ratio at 3.5). The E.C. of this salt treatment solution was $19 \mathrm{dS} / \mathrm{M}$ giving a soil E.C. of $5.1 \mathrm{dS} / \mathrm{M}$; measured immediately following each submersion using a Field Scout E.C. meter (Spectrum Technologies, Plainfield, IL). The treatment continued for 21 days, with control or salt irrigation treatments occurring twice weekly, whereupon salt treated plants of the susceptible accession exhibited leaf-tip firing and both accessions exhibited slower growth rates. The samples were harvested $60 \mathrm{~min}$ following the final treatment, approximately three hours after sunrise. For shoot tissue, above ground plant material was harvested on an individual plant basis, briefly rinsed with deionized water, and frozen in liquid nitrogen. Root tissue was harvested by briefly rinsing away sand, cutting below the crown, and freezing in liquid nitrogen. Treated and control plants were harvested at the same time. Three plants from both accessions, both tissues, and for both conditions (salt treatment and control) were sampled, providing 24 samples in total.

\section{cDNA sequencing}

RNA was extracted from the 24 samples using the Direct-zol RNA extraction kit (Zymo Research, Irvine, CA), quantified using the Quantifluor RNA system (Promega, Madison, WI), and tested for quality with Experion RNA-chips (Bio-Rad, Hercules, CA). Messenger RNA was isolated using the Dynabeads mRNA Direct Micro kit from Life Technologies. Sequence libraries were prepared with the Ion Total RNA-Seq Kit v2, barcoded with the Ion Xpress RNA-Seq Barcode kit, and size-selected to 160-300 bp using a Blue Pippin (Sage Science, Beverly, MA) at the Center for Integrated Biosystems at Utah State University (Logan, UT). After pooling into four-sample groups, the libraries were sequenced on an Ion Torrent Proton using the PI Template OT2 Kit v3 and Ion PI Sequencing 200 Kit v3.

\section{Quality trimming and assembly}

Resulting sequences were sequentially trimmed and demultiplexed by barcode using the Torrent Suite software (Life Technologies, Grand Island, NY) and CLC Genomics Workbench (CLCbio, Aarhus, Denmark), and FastQC (http://www.bioinformatics.babraham.ac.uk/projects/fastqc/
) was used to assess quality of sequence reads. The sequential trimming first consisted of removal of the 5' $10 \mathrm{bp}$, followed by quality trimming (Phred-33) of scores less than 15 and removal of adaptors and barcodes, and finally the removal of sequences longer than $250 \mathrm{bp}$. Sequence reads less than 50 bp were also discarded. A multidimensional scaling (MDS) plot was constructed based on the top 500 Euclidian distances of Log2-counts-per-million for each pairwise comparison, using the LIMMA:plotMDS package of R [44]. Sequence reads from both accessions and all 24 libraries were combined into a de novo reference assembly using Trinity [45] as applied in CLC Workbench, with a Kmer size of 25, a bubble size of 300 , and a minimum assembly length at $200 \mathrm{bp}$. No further grouping of sequences was conducted so as to remain sensitive to differential expression of splice variants and paralogs.

\section{Differential expression analysis}

Sequence reads from each sample were aligned to the reference using Bowtie implemented in RSEM [46], and expression values calculated using the ExpectationMaximization algorithm in RSEM [47]. The fragment length mean and the fragment length standard deviation were calculated separately for each sample and used to parameterize RSEM. A matrix of expression values was created in RSEM and differential gene expression assessed with Bioconductor package EBseq. Read counts were normalized to total sequence numbers using a median normalization as per Anders et al. [48], and normalized read counts are shown in the data and supplemental tables. The posterior probabilities of being differentially expressed were calculated for each transcript with the EBTest function. Criteria for keeping sequences for consideration were: at least 2 -fold expression difference between pairwise comparisons, a corrected false discovery rate less than 0.05, and at least one side of each pairwise comparison having average normalized counts greater than 50 . Root and shoot studies were considered separately.

Homology was based on BLASTx comparisons to the non-redundant database (July 1, 2014) using a threshold of $\mathrm{E}<10^{-5}$. GO mapping, annotation, and enrichment tests were conducting using BLAST2GO Pro v3.0 following default parameters (Biobam, Valencia, Spain). For graphing, GO terms were filtered such that greater than $2 \%$ of the total sequences must match the GO term to be included in the graph; otherwise sequences were included in the other category.

Transcription factors detection utilized profile hidden markov models in HMMER 3.1b2. Hidden markov models were obtained from the European Molecular Biology Lab-European Bioinformatics Institute PFAM database [49]. The de novo assembled transcriptome was searched for MYB (PF00249), 
bHLH (PF00010), Homeobox (PF00046), AP2 (PF00847), WRKY (PF03106), ERF (PF04404), NAC (PF01849) and $\mathrm{C} 2 \mathrm{H} 2$ zinc finger (PF00096) transcription factors using default settings of HMMsearch. Sequences matching a transcription factor hidden markov model profile with an e-value $<0.01$ and a domain e-value $<0.01$ were further analysed. These sequences were combined with GO term extractions to constitute the transcription factor dataset. Heat maps of groups of transcripts were constructed with Euclidean distances using the heatmap2 function in the gplots package in R [50]. Sample expression values were first transformed to $\log _{2}$, with zero expression values transformed by the addition of 1 to allow for the $\log$ transformation.

\section{Availability of supporting data}

The raw cDNA reads are available at NCBI under Bioproject number PRJNA296482 and SRA accession SRP065498.

\section{Additional files}

Additional file 1: Table S1. Normalized expression values for differentially expressed transcripts detected among 24 Kentucky bluegrass root tissue samples. (XLSX $1085 \mathrm{~kb}$ )

Additional file 2: Table S2. Normalized expression values for differentially expressed transcripts detected among 24 Kentucky bluegrass shoot tissue samples. (XLSX 2558 kb)

Additional file 3: Table S3. Prioritized differentially expressed transcripts from root tissue, BLASTx-based annotation, GO terms, and average normalized expression values of two Kentucky bluegrass accessions under control and salt treated conditions. (XLSX $44 \mathrm{~kb}$ )

Additional file 4: Table S4. Prioritized differentially expressed transcripts from shoot tissue, BLASTx-based annotation, GO terms, and average normalized expression values of two Kentucky bluegrass accessions under control and salt treated conditions. (XLSX $90 \mathrm{~kb}$ )

\section{Competing interests}

The authors declare that they have no competing interests.

\section{Author's contributions}

SB and PJ conceived and designed the study. KA and SB performed the data analyses with contributions from JR, SW, and PJ. SB and KA wrote the final manuscript. All authors read and approved the final manuscript.

\section{Acknowledgements}

We would like to thank Shyam Shridar for assistance in sample preparation and collection. The project was partially funded by the United States Golf Association.

\section{Author details}

'USDA-ARS Forage and Range Research Laboratory, 700 North 1100 East, Logan, UT 84322-6300, USA. ²Department of Agronomy and Horticulture, University of Nebraska, Lincoln, NE, USA. ${ }^{3}$ USDA-ARS Floral and Nursery Plants Research Unit, Beltsville, MD, USA. ${ }^{4}$ Department of Plants, Soils, and Climate, Utah State University, Logan, UT, USA.

Received: 23 September 2015 Accepted: 6 January 2016 Published online: 13 January 2016

\section{References}

1. Huff DR. Kentucky bluegrass. In: Casler MD, Duncan RR, editors. Turfgrass biology, genetics, and breeding. Hoboken: John Wiley and Sons Inc; 2003. p. 27-38.

2. Comstock JP, Ehleringer JR. Plant adaptation in the Great-Basin and Colorado plateau. Great Basin Naturalist. 1992;52(3):195-215.

3. Marcum KB. Use of saline and non-potable water in the turfgrass industry: constraints and developments. Agric Water Manage. 2006;80(1-3):132-46.

4. Lockett AM, Devittz DA, Morris RL. Impact of reuse water on golf course soil and turfgrass parameters monitored over a 4.5-year period. Hortscience. 2008:43(7):2210-8

5. Alshammary SF, Qian YL, Wallner SJ. Growth response of four turfgrass species to salinity. Agric Water Manage. 2004;66(2):97-111.

6. Horst GL, Taylor RM. Germination and initial growth of Kentucky bluegrass in soluble salts. Agron J. 1983;75(4):679-81.

7. Robins JG, Bushman BS, Waldron BL, Johnson PG. Variation within Poa Germplasm for salinity tolerance. Hortscience. 2009:44(6):1517-21.

8. Poss JA, Russell WB, Bonos SA, Grieve CM. Salt tolerance and canopy reflectance of Kentucky bluegrass cultivars. Hortscience. 2010;45(6):952-60.

9. Qian YL, Wilhelm SJ, Marcum KB. Comparative responses of two Kentucky bluegrass cultivars to salinity stress. Crop Sci. 2001:41(6):1895-900.

10. Marcum KB. Physiological adaptations of turfgrasses to salinity stress. In: Pessarakli M, editor. Turfgrass management and physiology. Raton: CRC Press; 2008.

11. Koch MJ, Bonos SA. An overhead irrigation screening technique for salinity tolerance in cool-season turfgrasses. Crop Sci. 2010;50(6):2613-9.

12. Torello WA, Rice LA. Effects of NACL stress on proline and cation accumulation in salt sensitive and tolerant turfgrasses. Plant and Soil. 1986;93(2):241-7.

13. Carrow RN, Duncan RR. Salt-affected turfgrass sites: assessment and management. Hoboken: John Wiley and Sons Inc:; 1998.

14. Koch MJ, Huang BR, Bonos SA. Salinity tolerance of Kentucky bluegrass cultivars and selections using an overhead irrigated screening technique. Crop Sci. 2011;51(6):2846-57.

15. Arghavani M, Kafi M, Babalar M, Naderi R, Hoque MA, Murata Y. Improvement of salt tolerance in Kentucky bluegrass by trinexapac-ethyl. Hortscience. 2012:47(8):1163-70.

16. Yang ZM, Yu J, Merewitz E, Huang BR. Differential effects of abscisic acid and glycine betaine on physiological responses to drought and salinity stress for two perennial grass species. J Am Soc Hort Sci. 2012;137(2):96-106.

17. Bushman BS, Warnke SE, Amundsen KL, Combs KM, Johnson PG. Molecular markers highlight variation within and among Kentucky bluegrass varieties and accessions. Crop Sci. 2013;53(5):2245-54.

18. Jamil A, Riaz S, Ashraf M, Foolad MR. Gene expression profiling of plants under salt stress. Crit Rev Plant Sci. 2011;30(5):435-58.

19. Munns R. Genes and salt tolerance: bringing them together. New Phytologist. 2005;167(3):645-63.

20. Zeng Q, Ling Q, Fan L, Li Y, Hu F, Chen J, et al. Transcriptome profiling of sugarcane roots in response to low potassium stress. PLoS One. 2015:10(5):e0126306.

21. Xiong $L$, Zhu JK. Abiotic stress signal transduction in plants: Molecular and genetic perspectives. Physiol Plant. 2001;112(2):152-66.

22. Maathuis FJM. Sodium in plants: perception, signalling, and regulation of sodium fluxes. J Exp Bot. 2014:65(3):849-58.

23. Hasegawa PM, Bressan RA, Zhu JK, Bohnert HJ. Plant cellular and molecular responses to high salinity. Annu Rev Plant Physiol Plant Mol Biol. 2000:51:463-99.

24. Li JG, Li XJ, Guo L, Lu F, Feng XJ, He K, et al. A subgroup of MYB transcription factor genes undergoes highly conserved alternative splicing in Arabidopsis and rice. J Exp Bot. 2006;57(6):1263-73.

25. Mu RL, Cao YR, Liu YF, Lei G, Zou HF, Liao Y, et al. An R2R3-type transcription factor gene AtMYB59 regulates root growth and cell cycle progression in Arabidopsis. Cell Res. 2009;19(11):1291-304.

26. Reiser L, Sanchez-Baracaldo P, Hake S. Knots in the family tree: evolutionary relationships and functions of knox homeobox genes. Plant Mol Biol. 2000:42(1):151-66

27. Giri J, Vij S, Dansana PK, Tyagi AK. Rice A20/AN1 zinc-finger containing stress-associated proteins (SAP1/11) and a receptor-like cytoplasmic kinase (OsRLCK253) interact via A20 zinc-finger and confer abiotic stress tolerance in transgenic Arabidopsis plants. New Phytologist. 2011;191(3):721-32.

28. Wang $R$, Jing $W$, Xiao $L$, Jin $Y$, Shen $L$, Zhang $W$. The rice high-affinity potassium Transporter1;1 is involved in salt tolerance and regulated by an MYB-type transcription factor. Plant Physiol. 2015;168(3):1076-90. 
29. Jacoby RP, Taylor NL, Millar AH. The role of mitochondrial respiration in salinity tolerance. Trends Plant Sci. 2011;16(11):614-23.

30. Biswas MS, Mano J. Lipid peroxide-derived short-chain carbonyls mediate hydrogen peroxide-induced and salt-induced programmed cell death in plants. Plant Physiol. 2015;168(3):885-98.

31. Qi YC, Liu WQ, Qiu LY, Zhang SM, Ma L, Zhang H. Overexpression of glutathione S-transferase gene increases salt tolerance of arabidopsis. Russ J Plant Physiol. 2010;57(2):233-40.

32. Guo L, Devaiah SP, Narasimhan R, Pan X, Zhang Y, Zhang W, et al. Cytosolic glyceraldehyde-3-phosphate dehydrogenases interact with phospholipase D $\delta$ to transduce hydrogen peroxide signals in the Arabidopsis response to stress. Plant Cell. 2012;24(5):2200-12.

33. Zhang X-H, Rao X-L, Shi H-T, Li R-J, Lu Y-T. Overexpression of a cytosolic glyceraldehyde-3-phosphate dehydrogenase gene OsGAPC3 confers salt tolerance in rice. Plant Cell Tiss Organ Cult. 2011;107(1):1-11.

34. Ouellet F, Overvoorde PJ, Theologis A. IAA17/AXR3: Biochemical insight into an auxin mutant phenotype. Plant Cell. 2001:13(4):829-42.

35. Nakano T, Suzuki K, Fujimura T, Shinshi H. Genome-Wide Analysis of the ERF Gene Family in Arabidopsis and Rice. Plant Physiol. 2006;140(2):411-32.

36. Cheng XF, Wang ZY. Overexpression of COL9, a CONSTANS-LIKE gene, delays flowering by reducing expression of $\mathrm{CO}$ and $\mathrm{FT}$ in Arabidopsis thaliana. Plant J. 2005:43(5):758-68.

37. Dietz KJ, Tavakoli N, Kluge C, Mimura T, Sharma SS, Harris GC, et al. Significance of the V-type ATPase for the adaptation to stressful growth conditions and its regulation on the molecular and biochemical level. J Exp Bot. 2001:52(363):1969-80.

38. Sarda X, Tousch D, Ferrare K, Legrand E, Dupuis JM, Casse-Delbart F, et al. Two TIP-like genes encoding aquaporins are expressed in sunflower guard cells. Plant J. 1997;12(5):1103-11.

39. Jiang $X$, Leidi EO, Pardo JM. How do vacuolar NHX exchangers function in plant salt tolerance? Plant Signal Behav. 2010;5(7):792-5.

40. Alscher RG, Erturk N, Heath LS. Role of superoxide dismutases (SODs) in controlling oxidative stress in plants. J Exp Bot. 2002;53(372):1331-41.

41. Fatehi F, Hosseinzadeh A, Alizadeh H, Brimavandi T, Struik PC. The proteome response of salt-resistant and salt-sensitive barley genotypes to long-term salinity stress. Mol Biol Rep. 2012;39(5):6387-97.

42. Boursiac Y, Chen S, Luu D-T, Sorieul M, van den Dries N, Maurel C. Early effects of salinity on water transport in Arabidopsis roots. Molecular and cellular features of aquaporin expression. Plant Physiol. 2005;139(2):790-805.

43. Peel MD, Waldron BL, Jensen KB, Chatterton NJ, Horton H, Dudley LM. Screening for salinity tolerance in alfalfa: a repeatable method. Crop Sci. 2004:44(6):2049-53.

44. Ritchie ME, Phipson B, Wu D, Hu YF, Law CW, Shi W, et al. limma powers differential expression analyses for RNA-sequencing and microarray studies. Nucleic Acids Res. 2015;43(7):e47.

45. Haas BJ, Papanicolaou A, Yassour M, Grabherr M, Blood PD, Bowden J, et al. De novo transcript sequence reconstruction from RNA-seq using the Trinity platform for reference generation and analysis. Nat Protoc. 2013;8(8):1494-512.

46. Li B, Dewey CN. RSEM: accurate transcript quantification from RNA-Seq data with or without a reference genome. BMC Bioinformatics. 2011;12:323.

47. Leng N, Dawson JA, Thomson JA, Ruotti V, Rissman Al, Smits BMG, et al. EBSeq: an empirical Bayes hierarchical model for inference in RNA-seq experiments. Bioinformatics. 2013;29(8):1035-43.

48. Anders S, Huber W. Differential expression analysis for sequence count data. Genome Biol. 2010;11(10):R106.

49. Finn RD, Bateman A, Clements J, Coggill P, Eberhardt RY, Eddy SR, et al. Pfam: the protein families database. Nucleic Acids Res. 2014:42(D1):D222-30.

50. Team RC. R: A language and environment for statistical computing. Vienna: R Foundation for Statistical Computing; 2015.

\section{Submit your next manuscript to BioMed Central and we will help you at every step:}

- We accept pre-submission inquiries

- Our selector tool helps you to find the most relevant journal

- We provide round the clock customer support

- Convenient online submission

- Thorough peer review

- Inclusion in PubMed and all major indexing services

- Maximum visibility for your research

Submit your manuscript at www.biomedcentral.com/submit
Biomed Central 